SHORT NOTE

\title{
Heat shock proteins expression during thermal risk exposure in the xerothermic ant Formica cinerea
}

\author{
P ŚLIPIŃSKI, JJ POMORSKI, K KOWALEWSKA
}

Museum and Institute of Zoology, Polish Academy of Sciences, Warsaw, Poland

\author{
Article History \\ Edited by \\ Gilberto M. M. Santos, UEFS, Brazil \\ Received 05 May 2014 \\ Initial acceptance 19 January 2015 \\ Final acceptance 01 May 2015

\section{Keywords} \\ Formicidae, temperature, limits, stress, \\ resistance, physiology.

\section{Corresponding author} \\ Museum and Institute of Zoology \\ Polish Academy of Sciences \\ Wilcza 64, 00-679 Warsaw, Poland \\ E-Mail: piotrs@miiz.waw.pl
}

\begin{abstract}
The abiotic conditions of the desert habitat fluctuate in a circadian rhythm of hot days and cold nights. Species living in desert habitats evolved many adaptations to increase their chances of survival. However, abiotic conditions in xerothermic habitats of a temperate climate are much different. Diurnal fluctuations are not as strong, but animals have to cope with seasonal changes and hibernate during the winter, which may potentially influence their adaptations to critical temperature conditions. We attempted to assess heat resistance adaptations using the example of a widely distributed xerothermic ant Formica cinerea. Using Real-Time PCR, we measured the expression of three heat shock protein genes (Hsp60, Hsp75, Hsp90) and assessed the adaptations of $F$. cinerea to enable foraging in risk prone conditions. The analysis of gene expression using the Generalized Linear Model surprisingly indicated that there was no significant effect of temperature when comparing workers from the control $(23 \mathrm{O} C)$ with workers foraging on the surface of hot sand (47-54-C). As a next step we tried to estimate the threshold of a thermal resistance with the use of thermal chambers. Expression of all Hsps genes increase compare to the control group, expression of $\mathrm{Hsp} 60$ and $\mathrm{Hsp} 90$ continued up to $45^{\circ} \mathrm{C}$.
\end{abstract}

Sandy and arid landscapes are one of the most demanding environments for living organisms, leading to the evolution of many interesting adaptations in animal dwellers. In a longer perspective, food and water are elements limiting animal survival rate, but in the shorter - daily - perspective, temperature is an ultimate factor. For ectotherms (unable to actively control body temperature), inhabiting sandy habitats such as deserts or dunes, ground temperature is a factor limiting activity and survival rate (Lenoir et al., 2009). The temperature of a sand surface at the sun's zenith differs at every geographical range. For example, this temperature in the Sahara desert is even $74^{\circ} \mathrm{C}$, while in a sandy forest clearing of a temperate climate, can reach $54^{\circ} \mathrm{C}$, but in both cases, it is beyond the thermal optimum of most living organisms. Every animal exposed for a longer period of time to these conditions faces the same threat of experiencing heat stroke. Despite individual strategies of avoiding heat (digging burrows, raising the body, etc.), at a cellular level, all organisms induce heat shock proteins (Hsps) as molecular chaperones to protect their own proteins against denaturation (Feder \&
Hofmann, 1999). Hsps recognize and bind to other proteins in non-native conformations during denaturing stress, serving as molecular chaperones. In proposed study Hsps are used to asses a thermal risk during foraging in Formica cinerea.

$F$. cinerea is a typical thermophilic and xerophilic oligotope of dry open habitats. Field observations of $F$. cinerea workers foraging on hot soil during the summer led to developing the main working hypothesis that foraging in such demanding conditions in the case of $F$. cinerea is most probably correlated with a high level of cellular stress and thus the expression of Hsp. Before obtaining the results, the only question seemed to be: how risky is foraging in these particular conditions? The aim of the field work part, was to measure the Hsp expression level during worker foraging on the surface of hot sand, whereas the goal of the laboratory part, was to estimate the threshold of thermal resistance under laboratory conditions by exposing ants to high temperatures over a long period of time.

In field experiment individuals of $F$. cinerea were collected directly from the nest entrance in the morning when 
the nest temperature was low and the soil temperature around the nest was $23.5^{\circ} \mathrm{C}$ (control group). Another group of workers were collected from the hot soil in the middle of the sunny day (between 12:30 to 14:40 p.m.), when the soil surface temperature reached from $47^{\circ} \mathrm{C}$ to $54^{\circ} \mathrm{C}$ (see more detailed description of the material and methods in supplementary material). The Generalized Linear Model (in SPSS v. 20) with a linear scale response and identity link function was applied to compare both groups. Data before the GLM were log transformed. GLM model indicate that that there is no significant effect ( $p=$ 0.122) of group (control/workers form hot sand), and therefore no difference in Hsps expression between ants collected in the morning when the external temperature was low $\left(23^{\circ} \mathrm{C}\right)$ and ants taken from hot sand during the middle of the day when the surface temperature was very high (up to $47-54^{\circ} \mathrm{C}$ ). No effect of group also means, in this case, no effect of temperature. The Hsp family factor (Hsp60, Hsp75, Hsp90) had a strong effect $(p<0.001)$ on expression. The graph presents (Fig 1) an increase of Hsp75 and Hsp90 expression indicating some physiological response to risk-prone conditions, whereas Hsp60 remained at the same level. The interaction between group and Hsp family was not significant $(\mathrm{p}=0.587)$. No effect of temperature rejects the main working hypothesis that foraging on hot soil is correlated with a high level of thermal stress and thus the significant increase of Hsp expression. At the same time, this result generates at least two additional questions: (1) what really is the threshold of thermal resistance in this species and (2) if $F$. cinerea workers do not suffer from thermal stress during foraging on a hot soil surface, are they physiologically adapted to avoid this kind of stress? The laboratory part of this experiment can help in understanding the physiological barrier of thermal resistance and answer - at least partially - the issues raised.

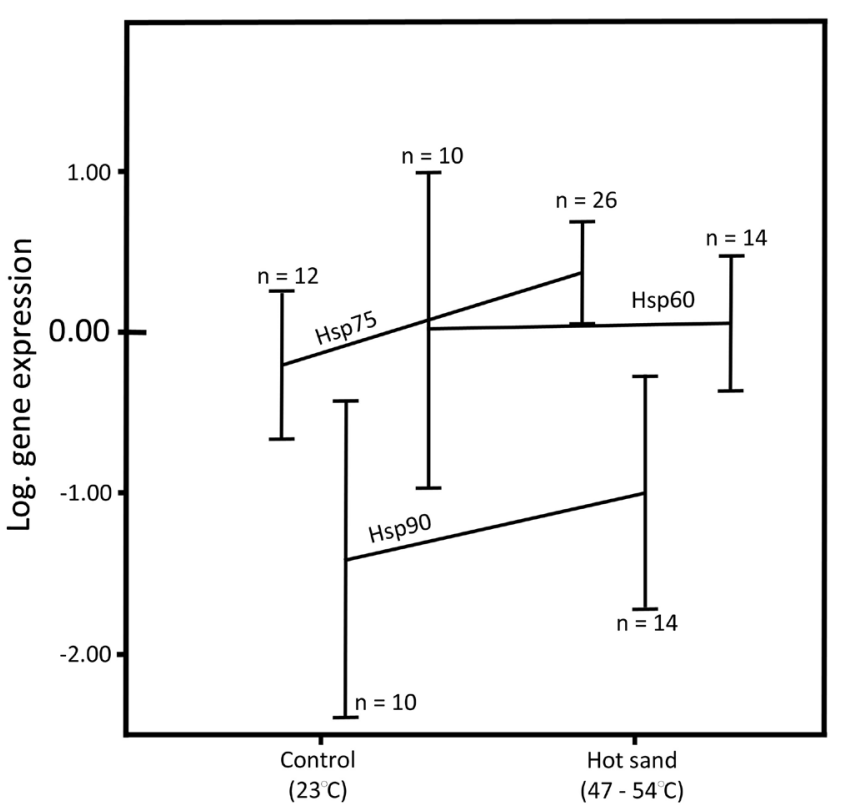

Fig 1. Field experiment - expression of Hsp60, Hsp90 and Hsp75 in $F$. cinerea workers during foraging in field conditions. Mean log. value of gene expression and $95 \%$ confidence interval $(\mathrm{Cl})$ error bars.
In laboratory experiment workers of $F$. cinerea were collected in the morning and they originated from the same colonies as the individuals used in the field experiment. Immediately after transport, the ants were placed in thermal chambers for two hours at $40^{\circ} \mathrm{C}$ or $45^{\circ} \mathrm{C}$ and put in RNAlater after thermal stress. Similarly like in field experiment the Generalized Linear Model with a linear scale response and identity link function was applied. GLM model indicates significant effect of the temperature and gene family on the Hsp expression level. Interaction was close to significant $(\mathrm{p}=0.055)$ indicating that different Hsp genes respond differently to applied temperatures. The expression of Hsp60 and Hsp90 increased from $23^{\circ} \mathrm{C}$ to $45^{\circ} \mathrm{C}$, however the expression of $\mathrm{Hsp} 75$ reached maximum already in $40^{\circ} \mathrm{C}$, demonstrating that a temperature of $40^{\circ} \mathrm{C}$ is already a strong enough factor for the maximum expression of this gene (Fig 2). Comparing this result with the field part of the experiment - where Hsp75 expression was the highest in a group from hot soil - it is most probable that Hsp75 is most "sensitive" to heat stress in temperatures up to $40^{\circ} \mathrm{C}$. Similar results were

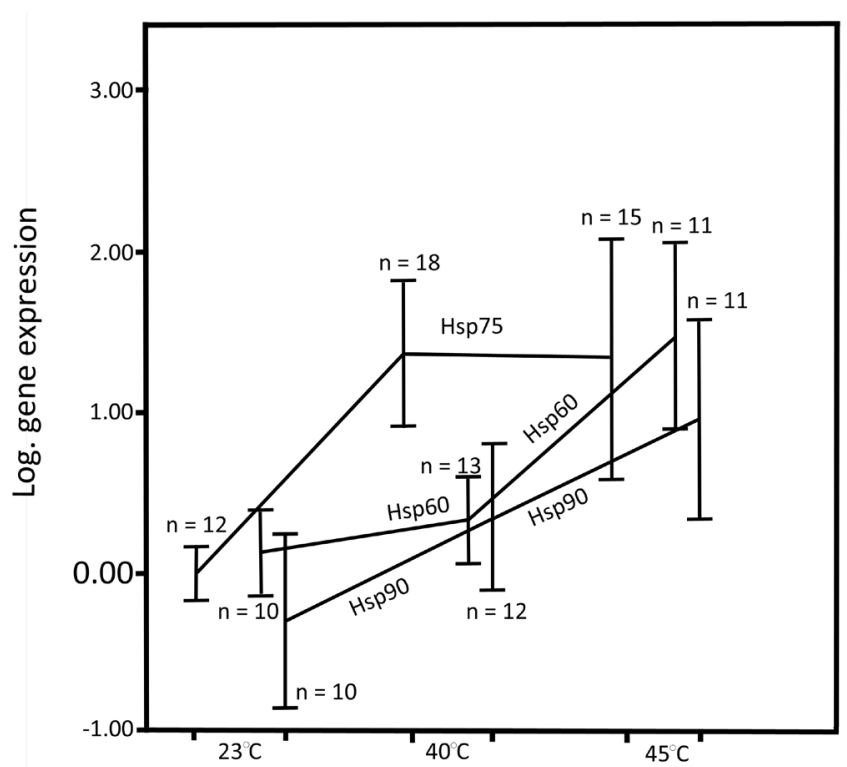

Fig 2. Laboratory experiment - expression of Hsp60, Hsp75 and Hsp90 in $F$. cinerea workers in $40^{\circ} \mathrm{C}$ and $45^{\circ} \mathrm{C}$ thermal chambers comparing to control $\left(23^{\circ} \mathrm{C}\right)$. Mean log. value of gene expression and $95 \%$ confidence interval $(\mathrm{Cl})$ error bars.

obtained by Gehring \& Wehner (1995) on Hsp70 during the study of Cataglyphis. The authors interpret this protein synthesis and accumulation in low temperatures as a preadaptation of the studied species to foraging in rapidly changed conditions when workers emerge from a relatively cold nest (where Hsp accumulation already starts) to lethal outdoor temperatures. The authors also emphasize that Hsp70 synthesis in $F$. polyctena stops above the temperature of $39^{\circ} \mathrm{C}$, whereas it continues up to $45^{\circ} \mathrm{C}$ in Cataglyphis, making this species more heat shock resistant. Following this argument, in the case of our study with $F$. cinerea, the synthesis of Hsp75 also reach maximum at a temperature of $40^{\circ} \mathrm{C}$, but the expression of the other two genes 
(Hsp60 and Hsp90) increases up to $45^{\circ} \mathrm{C}$ (as in Cataglyphis), also demonstrating some physiological adaptations to high temperatures. This result partially answers the question about physiological adaptations of $F$. cinerea to thermal stress in field conditions. The limits of thermal resistance was measured by the number of ant demises resulting from temperature exposure. Four individuals (out of 20) of $F$. cinerea did not survive to the end of the thermal exposure in $40^{\circ} \mathrm{C}$ and ultimately died as a result of heat stroke (or/and desiccation).

The results of the experiment suggests that expression of Hsps in workers of $F$. cinerea foraging in conditions of thermal risk is similar to control group. Is it an effect of short exposition on lethal temperatures - because ants simply shorten they foraging time or just avoiding warm patches during foraging - is totally not clear. Observation during the field work suggest that many workers stay in the nest during most hazardous part of the day and only some part is foraging, but what proportion and what individuals (maybe only older and more experienced are foraging) is also a mystery. Outcome of the experiment indicate that workers of $F$. cinerea are to some point physiologically adapted to cope with high temperatures but the level of such an adaptation cannot be specified by one experiment and require further effort. Most present and past experiment was conducted on typical desert animals but the knowledge about the thermal response in a species from temperate climate is somehow neglected.

\section{References}

Feder, M. E. \& Hofmann, G. E. (1999). Heat-shock proteins, molecular chaperones, and the stress response: Evolutionary and ecological physiology. Annual Review of Physiology, 61: 243-282.

Gehring, W. J. \& Wehner, R. (1995). Heat-shock proteinsynthesis and thermotolerance in Cataglyphis, an ant from the sahara desert. Proceedings of the National Academy of Sciences U.S.A., 92: 2994-2998.

Lenoir, A., Aron, S., Cerdá, X. \& Hefetz, A. (2009). Cataglyphis desert ants: a good model for evolutionary biology in Darwin's anniversary year - a review. Israel Journal of Entomology, 39: 1-32.

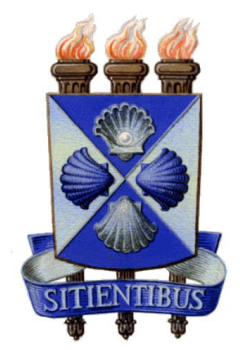

